\title{
Premalignant lesions, basal cell carcinoma and melanoma in patients with cutaneous squamous cell carcinoma
}

\author{
Niina Korhonen ${ }^{1}$ (D) $\cdot$ Leea Ylitalo ${ }^{1,2} \cdot$ Tiina Luukkaala $^{3} \cdot$ Julius Itkonen $^{1} \cdot$ Henni Häihälä ${ }^{1} \cdot J^{\prime}$ ha Jernman ${ }^{4}$. \\ Erna Snellman ${ }^{1}$. Johanna Palve ${ }^{5}$
}

Received: 18 December 2019 / Revised: 23 May 2020 / Accepted: 31 July 2020 / Published online: 9 August 2020

(c) The Author(s) 2020

\begin{abstract}
The incidence of keratinocyte carcinomas is increasing worldwide and currently there is no standardised strategy for the follow-up of patients with multiple tumours. The objective of this study was to assess the prevalence of premalignant lesions, i.e., actinic keratosis and Bowen's disease, as well as basal cell carcinoma (BCC) and cutaneous melanoma (CM) among patients with cutaneous squamous cell carcinoma (cSCC). Pathology database search was performed to identify all cSCC patients diagnosed in the Pirkanmaa region of Finland in 2006-2015. Details of the patients and tumours were obtained through medical record review. The cohort consisted of 774 patients with $1131 \mathrm{cSCC}$ tumours. Overall 559 patients (72\%) had premalignant lesions. A total of 316 patients $(41 \%)$ had BCC and $52 \%$ of these $(n=164)$ had more than one BCC tumour. 50 patients (6\%) had CM. Overall 180 cSCC patients (23\%) had no premalignant changes, BCC or CM. The median age of these patients was 6 years less than that of the patients with premalignant lesions $(p<0.001)$ or BCC $(p<0.001)$. The invasion depth of the tumours was deeper in the patients with only cSCC (median $3 \mathrm{~mm}$, interquartile range 2-6) than in those with premalignant lesions or BCC (median $2 \mathrm{~mm}$, interquartile range 1-3), $p<0.001$. CSCC patients have a high risk of developing multiple skin cancers and need long-term follow-up.
\end{abstract}

Keywords Cutaneous squamous cell carcinoma $\cdot$ Basal cell carcinoma $\cdot$ Cutaneous melanoma $\cdot$ Actinic keratosis $\cdot$ Bowen's disease

Niina Korhonen

niina.korhonen@fimnet.fi

1 Department of Dermatology and Allergology, Tampere University Hospital and Faculty of Medicine and Health Technology, Tampere University, Tampere, Finland

2 Department of Dermatology, Skin Cancer Unit, Helsinki University Central Hospital, Helsinki, Finland

3 Research, Development and Innovation Center, Tampere University Hospital and Health Sciences, Faculty of Social Sciences, Tampere University, Tampere, Finland

4 Department of Pathology, Tampere University and Fimlab Laboratories, Tampere, Finland

5 Department of Plastic Surgery, Tampere University Hospital and Faculty of Medicine and Health Technology, Tampere University, Tampere, Finland

\section{Introduction}

The incidence of keratinocyte carcinomas, i.e., cutaneous squamous cell carcinomas (cSCC) and basal cell carcinomas (BCC), is increasing worldwide [1]. Although cSCC and BCC partially share similar risk factors [2, 3], they have fundamentally distinct and heterogeneous disease characteristics. CSCCs can emerge de novo but commonly originate from precursor lesions such as actinic keratosis (AK) and cSCC in situ, also known as Bowen's disease (BD) [4]. There is a low risk of malignant progression for any given $\mathrm{AK}$ or $\mathrm{BD}$ and the presence of these precursor lesions predicts an increased risk of developing keratinocyte carcinoma or cutaneous melanoma $(\mathrm{CM})$ compared with a matched population [5-7].

It has been reported previously that patients with keratinocyte carcinoma have a significantly greater risk of subsequent skin cancer [3, 8-11]. Less is known, however, about cSCC patients in particular and the impact of multiple cSCC tumours on the subsequent cancer risk has remained unknown. The 
aim of this study was to assess the prevalence of premalignant lesions (AK and $\mathrm{BD}$ ), BCC and $\mathrm{CM}$ among $\mathrm{CSCC}$ patients in a Finnish regional university hospital cohort which included patients with multiple cSCC tumours.

\section{Materials and methods}

To identify all the cSCC patients in the Pirkanmaa region of Finland, a pathology database search was performed at Fimlab Laboratories for histopathological diagnoses of 'cutaneous squamous cell carcinoma' (cSCC) between 1 January 2006 and 31 December 2015. In 2006, the population of Pirkanmaa was 473,490 at the beginning of that period and 506,114 in the last year, 2015 [12]. We reviewed the clinical records of Tampere University Hospital of all identified cSCC patients. This retrospective study was approved by the institutional review board of Tampere University Hospital, Finland.

Data obtained from the cSCC patients included patient age at diagnosis of the primary tumour, gender and associated diseases (particularly immunosuppression). Features of the cSCC tumours themselves, including anatomic location, degree of differentiation and depth of invasion, were also noted. Details of the cohort and time trends observable in it have been reported previously [13].

Patients were indicated as having $\mathrm{AK}, \mathrm{BD}, \mathrm{BCC}$ or $\mathrm{CM}$ if a prior history or current treatment until the end of the study period of such a lesion was recorded in the clinical notes. The total numbers of BCC and CM cases were collected for each patient. Patients were indicated as positive for AK and/ or BD based on the clinical records, regardless of whether the lesion had been histologically confirmed or not. AK and $\mathrm{BD}$ were referred to as premalignant lesions distinguishing these from the invasive form of $\mathrm{cSCC}$.

Categorical data were described by number of patients or number of tumours with percentages, and differences between such variables were tested with Pearson's chisquare test or Fisher's exact test. Due to the skew distributions, continuous variables were described by medians with interquartile ranges and tested with the Mann-Whitney test. All the tests were two-sided and a $p$ value $<0.05$ was considered significant, except that $p<0.001$ was required for significance when Bonferroni correction was used in the interpretation of the results due to the multi-testing of $\mathrm{AK} / \mathrm{BD}$, $\mathrm{BCC}$ and/or CM. Statistical analyses were performed using IBM SPSS Statistics for Windows (version 23.0, Armonk, NY, USA, IBM Corp.).

\section{Results}

After 567 diagnostic duplicates, i.e., overlapping data on biopsy and excision of the same case of cSCC, were excluded, the cohort consisted of 774 patients with 1131
cSCC tumours. A total of 81 (11\%) patients were immunosuppressed, due to organ transplantation $(n=37)$, rheumatoid arthritis $(n=23)$, chronic leukaemia $(n=10)$ or lymphoma $(n=11)$.

\section{$A K$ and BD in CSCC patients}

Out of the 559 patients ( $72 \%$ of the cohort) who had premalignant lesions (AK and/or BD), 204 had only AK, and 46 only BD (Table 1 ). The remaining 309 patients had both. The median age of the cSCC patients with premalignant lesions was 82 years (interquartile range $76-86$ years), and the prevalence of such lesions increased with age (Table 1).

The number of cSCC tumours recorded per patient during the study period ranged between 1 and 26 , and patients with multiple cSCC tumours more commonly had premalignant lesions than those with a single tumour (Table 1).

If the tumour was located on the face (excluding lips, eyelids and ears) or upper extremity the patient was most likely to have premalignant lesions (Table 2). A total of 358 tumours had an invasion depth of $2 \mathrm{~mm}$ or less and in $85 \%$ of these cases the patient had premalignant lesions (Table 2). If the tumour was thicker than $4 \mathrm{~mm}$, however, $55 \%$ of the patients had premalignant lesions. There was a tendency for patients with poorly tumour differentiation to have less premalignant lesions (Table 2).

\section{BCC and CM in CSCC patients}

Overall, 316 patients ( $41 \%$ of the cohort) had BCC (Table 1), these having a median age of 82 years (interquartile range 76-87 years). The number of BCC tumours per patient ranged from 1 to 19 , with over half of the patients with $\mathrm{BCC}$ ( $n=164,52 \%)$ having more than $1 \mathrm{BCC}$ tumour. Patients with multiple cSCC tumours during the study period were more likely to have BCC (Table 1).

A total of 50 patients (6\% of the cohort) had CM (Table 1). The presence of CM was not associated with any specific location of cSCC tumour (Table 2), except that when the tumour was located on upper extremity the patient was slightly more likely to have CM than with some other location. The most common subtype of $\mathrm{CM}$ was superficial spreading melanoma (41\%) while $18 \%$ were lentigo malignas, $10 \%$ in situ melanomas, $10 \%$ nodular melanomas, $2 \%$ lentigo maligna melanomas and $20 \%$ were not specified. The mean Breslow thickness was $1.3 \mathrm{~mm}$.

\section{Combination of skin cancers}

A total of 284 patients (37\%) had both premalignant changes and BCC (Fig. 1). CSCC patients with CM generally had premalignant changes (46/50 patients, $92 \%$ ) and also commonly had BCC (30/50 patients, $60 \%)$. A total of 29 patients 
Table 1 Patient characteristics and prevalence of premalignant lesions (actinic keratosis and/or Bowen`s disease, i.e., AK/BD), basal cell carcinoma (BCC) and cutaneous melanoma (CM) (patients $N=774$ )

\begin{tabular}{|c|c|c|c|c|c|c|c|}
\hline & \multirow[t]{2}{*}{ Total $N$} & \multicolumn{2}{|c|}{$\mathrm{AK} / \mathrm{BD}(n=559)$} & \multicolumn{2}{|c|}{$\operatorname{BCC}(n=316)$} & \multicolumn{2}{|c|}{$\mathrm{CM}(n=50)$} \\
\hline & & $n(\%)$ & $p$ & $n(\%)$ & $p$ & $n(\%)$ & $p$ \\
\hline Sex & & & 0.225 & & 0.003 & & 0.027 \\
\hline Men & 394 & $277(70)$ & & $181(46)$ & & $33(8)$ & \\
\hline Women & 380 & $282(74)$ & & $135(36)$ & & $17(5)$ & \\
\hline Age, years & & & $<0.001$ & & 0.003 & & 0.368 \\
\hline$<60$ & 35 & $11(31)$ & & $4(11)$ & & $1(3)$ & \\
\hline $60-69$ & 84 & $46(55)$ & & $33(39)$ & & $3(4)$ & \\
\hline $70-79$ & 238 & $175(74)$ & & $95(40)$ & & $21(9)$ & \\
\hline $80-89$ & 323 & $255(79)$ & & $138(43)$ & & $19(6)$ & \\
\hline$\geq 90$ & 94 & $72(77)$ & & $46(49)$ & & $6(6)$ & \\
\hline Immunosuppression & & & 0.359 & & 0.018 & & 0.399 \\
\hline No & 693 & $497(72)$ & & $273(39)$ & & $43(6)$ & \\
\hline Yes & 81 & $62(77)$ & & $43(53)$ & & $7(9)$ & \\
\hline Number of SCC tumours & & & $<0.001$ & & $<0.001$ & & 0.030 \\
\hline 1 & 588 & $400(68)$ & & $217(37)$ & & $32(5)$ & \\
\hline 2 & 116 & $95(82)$ & & $51(44)$ & & $8(7)$ & \\
\hline 3 & 42 & $38(91)$ & & $26(62)$ & & 7 (17) & \\
\hline$\geq 4$ & 28 & $26(93)$ & & $22(79)$ & & $3(11)$ & \\
\hline
\end{tabular}

Differences between groups were tested using Pearson's chi-square test or Fisher's exact test

$N$ total number of patients, $n$ number of $\mathrm{AK} / \mathrm{BD}, \mathrm{BCC}$ or $\mathrm{CM}$
(4\% of the cohort) had lesions of all types (premalignant lesions, BCC and CM) (Fig. 1).

Of all the 774 cSCC patients, 180 patients (23\%) had no premalignant changes, BCC or CM (Fig. 1). The median age of these patients was 76 (interquartile range 66-84), i.e., they were 6 years younger than the patients with premalignant lesions $(p<0.001)$ and those with $\mathrm{BCC}(p<0.001)$. Compared to with the patients with premalignant lesions, BCC or CM, these patients had less cSCC tumours per patient during the study period ( $p<0.001)$, as 158 of them (88\%) had only 1 tumour. The invasion depth of the tumours was deeper in the patients with only cSCC (median $3 \mathrm{~mm}$, interquartile range 2-6, measured from 132 tumours out of 208) than in those with premalignant lesions or BCC (median $2 \mathrm{~mm}$, interquartile range 1-3, measured from 541 out of 923 tumours), $p<0.001$.

\section{Discussion}

A total of $72 \%$ of the cSCC patients in this cohort had premalignant lesions and $44 \%$ had a different skin cancer (BCC and/or CM) in addition to cSCC. Since the patients with premalignant lesions commonly had multiple cSCCs and multiple BCCs, it seems that the diverse spectrum of keratinocyte carcinoma and its precursors accumulates in the same patients. The cSCC patients less often had CM, but in those cases they generally also had premalignant lesions and commonly BCC as well. It has been reported previously that a history of keratinocyte carcinoma is among the strongest risk factors for subsequent $\mathrm{BCC}, \mathrm{SCC}$ and to a lesser extent CM $[2,3,14,15]$. This suggests a partially shared aetiology and set of risk factors between different types of cutaneous malignancies which include exposure to UV radiation, genetic susceptibility and immunosuppression [3, 14, 16]. Furthermore, it has been reported that the risk of a subsequent new keratinocyte carcinoma with time is substantially lower after a first tumour diagnosis than after a non-first diagnosis [17]. The EDF-EADO-EORTC consensus group proposes follow-up clinical examinations for cSCC patients based on the risk profile of cSCC tumours [4]. For patients with multiple cutaneous malignancies and precursor lesions no consensus on the follow-up schedule exists.

The cSCC patients with premalignant lesions and BCCs were older than the others. It is known that the prevalence of AK increases with age, but it is likely that the prevalence has been underestimated [5]. Almost 38\% of the participants in a Dutch population-based study (mean age 72 years) had one or more AK [18] and the prevalence of AK among people aged 70 or over in an Austrian study was over 50\% [19]. It has been suggested that annual rates of progression from AK to cSCC range from $0 \%$ to $0.075 \%$ per lesion, with a risk of up to $0.53 \%$ per lesion in patients with a prior history of keratinocyte carcinoma [20]. Regardless of the grade of the lesions, it is not possible to predict which AKs will progress to invasive carcinomas [21]. Since over half of our patients with premalignant lesions had both AK and BD, this could mean that many patients had field cancerization, 
Table 2 Characteristics of cSCC tumours and prevalence of premalignant lesions (actinic keratosis and/or Bowen`s disease, i.e., AK/BD), basal cell carcinoma $(\mathrm{BCC})$ and cutaneous melanoma $(\mathrm{CM})$ in the patient (tumours $N=1131$ )

\begin{tabular}{|c|c|c|c|c|c|c|c|}
\hline & \multirow{2}{*}{$\begin{array}{l}\text { Total } \\
(N=1131) \\
N\end{array}$} & \multicolumn{2}{|c|}{$\mathrm{AK} / \mathrm{BD}(n=880)$} & \multicolumn{2}{|c|}{$\mathrm{BCC}(n=554)$} & \multicolumn{2}{|c|}{$\mathrm{CM}(n=80)$} \\
\hline & & $n(\%)$ & $p$ & $n(\%)$ & $p$ & $n(\%)$ & $p$ \\
\hline \multicolumn{8}{|l|}{ Tumour location } \\
\hline Lip & 52 & $37(71)$ & 0.237 & $15(29)$ & 0.003 & $2(4)$ & 0.576 \\
\hline Eyelid & 11 & $6(55)$ & 0.074 & $4(36)$ & 0.400 & $2(18)$ & 0.180 \\
\hline Ear & 106 & $77(73)$ & 0.179 & $57(54)$ & 0.300 & $9(9)$ & 0.550 \\
\hline Face & 564 & $466(83)$ & $<0.001$ & $272(48)$ & 0.612 & $40(7)$ & 0.980 \\
\hline Scalp and neck & 91 & $79(87)$ & 0.031 & $46(51)$ & 0.755 & $4(4)$ & 0.299 \\
\hline Trunk & 61 & $51(84)$ & 0.262 & $40(66)$ & 0.008 & $4(7)$ & 1.000 \\
\hline Upper extremity & 136 & $120(88)$ & 0.002 & $81(60)$ & 0.009 & $16(12)$ & 0.023 \\
\hline Lower extremity & 68 & $39(57)$ & $<0.001$ & $34(50)$ & 0.863 & $3(4)$ & 0.622 \\
\hline Anogenital area & 31 & $4(13)$ & $<0.001$ & $5(16)$ & $<0.001$ & $0(0)$ & 0.162 \\
\hline Oral cavity & 11 & $1(10)$ & $<0.001$ & $0(0)$ & 0.001 & $0(0)$ & 1.000 \\
\hline Tumour differentiation & & & $0.029 / 0.049$ & & $0.121 / 0.074$ & & $0.633 / 0.469$ \\
\hline Well & 521 & 402 (77) & & $272(52)$ & & $34(7)$ & \\
\hline Moderate & 450 & 357 (79) & & $205(46)$ & & $31(7)$ & \\
\hline Poorly & 89 & $60(67)$ & & $39(44)$ & & $9(10)$ & \\
\hline Unknown & 71 & $61(86)$ & & $38(54)$ & & $6(9)$ & \\
\hline Invasion depth (in mm) & & & $<0.001 /<0.001$ & & $0.071 / 0.040$ & & $0.751 / 0.595$ \\
\hline$<1$ & 45 & $42(92)$ & & $25(56)$ & & $4(9)$ & \\
\hline $1.0-2.0$ & 313 & $264(84)$ & & $161(51)$ & & $26(8)$ & \\
\hline $2.1 .0-4.0$ & 203 & $149(73)$ & & $98(48)$ & & $11(5)$ & \\
\hline$>4.0$ & 112 & $61(55)$ & & $41(37)$ & & $7(6)$ & \\
\hline Unknown & 458 & $364(80)$ & & $229(50)$ & & $32(7)$ & \\
\hline
\end{tabular}

Differences between groups were tested using Pearson's chi-square test or Fisher's exact test. P-values for tumour differentiation and invasion depth with/without unknown group

$N$ total number of tumours, $n$ number of $\mathrm{AK} / \mathrm{BD}, \mathrm{BCC}$ or $\mathrm{CM}$

Fig. 1 Combinations of tumour types among the cSCC patients. $A K / B D$ actinic keratosis and/ or Bowen's disease, $B C C$ basal cell carcinoma, $C M$ cutaneous melanoma
cSSC patients ( $N=774)$

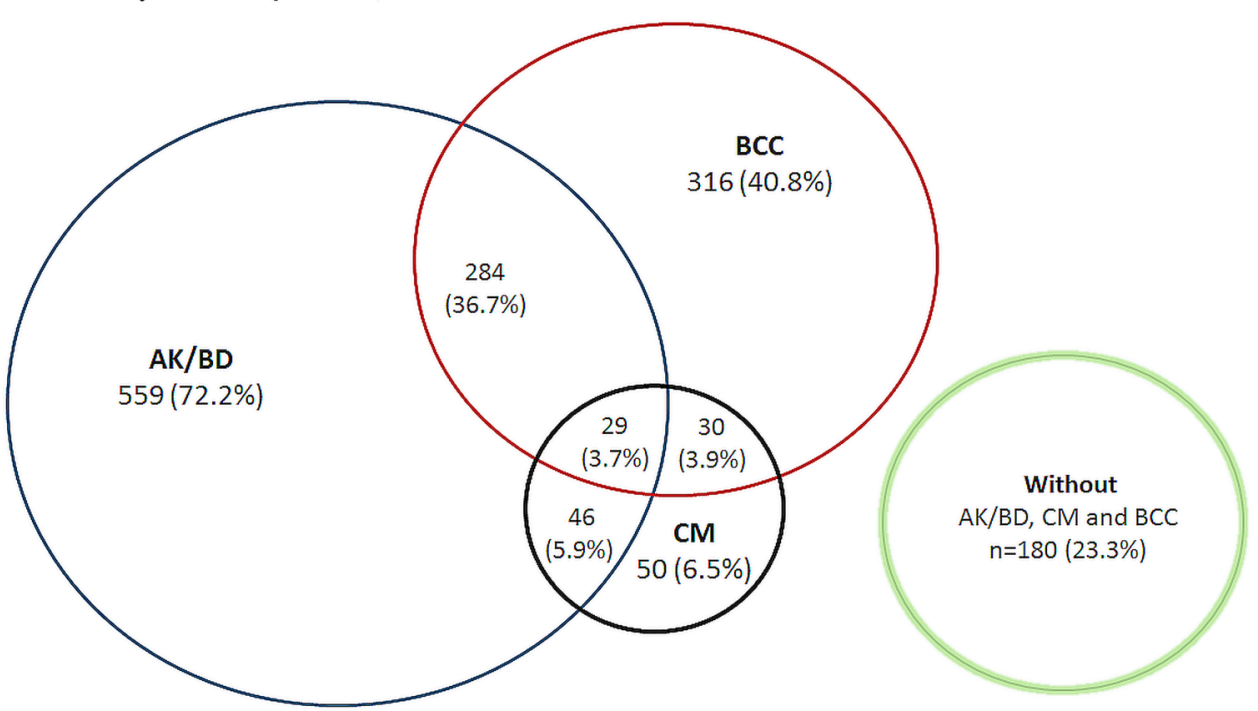


which could explain why multiple $\mathrm{cSCC}$ and $\mathrm{BCC}$ tumours emerged in these patients. There has been some debate about whether all AKs should be treated to prevent progression to cSCC [22] but at least individuals with numerous lesions are most likely to benefit from treatment and more frequent follow-up [5, 18] and this represents a growing future healthcare challenge because of ageing populations.

The finding that the cSCC tumour was commonly located in an area exposed to the sun (face, scalp and neck or upper extremity) if the patient had premalignant lesions is line with the fact that cumulative lifetime exposure to UV radiation is the main risk factor for the development of $\operatorname{cSCC}[4,23]$. However, cSCC location in an area exposed to the sun was not closely associated with the prevalence of $\mathrm{BCC}$ in our cohort. BCCs were more common in the patients whose cSCCs were located in the trunk area or upper extremity. Subramaniam et al. reported that cSCCs occurred on body sites frequently exposed to sunlight, whereas BCCs occurred more often on sites of infrequent exposure, supporting the theory that lower doses of UV radiation can give rise to BCCs rather than cSCCs [24]. Furthermore, the patients in our cohort whose cSCC was located on an upper extremity were slightly more likely to have CM than those with their cSCC in other locations. In the light of these findings, cSCCs on the trunk or upper extremity could be considered signs of excessive UV exposure (with also high intermittent patterns) or an otherwise susceptible condition in the patient to be indicative of an increased risk of a variety of cutaneous malignancies.

Limitation of the study was that the information on the tumours was collected retrospectively, which meant that the numbers of premalignant lesions and their anatomical distribution could not be recorded nor could the data on the timeline on which these or other neoplasms emerged. Likewise, as the cohort was drawn from a single hospital, the results cannot be generalized.

In conclusion, a large subset of cSCC patients have a lifelong risk of developing multiple skin cancers and are in need of long-term follow-up and repeated courses of treatment. Counselling on sun avoidance and sun protection measures are essential to limit the increase in the number of types of skin cancer in the future. It is extremely important to examine the patient's whole body at follow up visits [25]. The treatment and follow-up of patients with photo-damaged skin, a sign of increased skin cancer risk, must be recognised as a future health care challenge.

Funding The study was financially supported by The Finnish Dermatological Society (a grant awarded to Dr. Korhonen). This organisation had no involvement in the design and conduct of the study; collection, management, analysis, and interpretation of the data; preparation, review, or approval of the manuscript; and decision to submit the manuscript for publication.

\section{Compliance with ethical standards}

Conflicting interests The Authors declare that there is no conflict of interest.

Open Access This article is licensed under a Creative Commons Attribution 4.0 International License, which permits use, sharing, adaptation, distribution and reproduction in any medium or format, as long as you give appropriate credit to the original author(s) and the source, provide a link to the Creative Commons licence, and indicate if changes were made. The images or other third party material in this article are included in the article's Creative Commons licence, unless indicated otherwise in a credit line to the material. If material is not included in the article's Creative Commons licence and your intended use is not permitted by statutory regulation or exceeds the permitted use, you will need to obtain permission directly from the copyright holder. To view a copy of this licence, visit http://creativecommons.org/licenses/by/4.0/.

\section{References}

1. Lomas A, Leonardi-Bee J, Bath-Hextall F (2012) A systematic review of worldwide incidence of nonmelanoma skin cancer. $\mathrm{Br}$ J Dermatol 166(5):1069-1080

2. Wu S, Cho E, Li WQ, Qureshi AA (2017) History of keratinocyte carcinoma and risk of melanoma: a prospective cohort study. J Natl Cancer Inst 109:4. https://doi.org/10.1093/jnci/djw268

3. van der Leest RJT, Hollestein LM, Liu L, Nijsten T, de Vries E (2018) Risks of different skin tumour combinations after a first melanoma, squamous cell carcinoma and basal cell carcinoma in dutch population-based cohorts: 1989-2009. J Eur Acad Dermatol Venereol 32(3):382-389

4. Stratigos A, Garbe C, Lebbe C et al (2015) Diagnosis and treatment of invasive squamous cell carcinoma of the skin: European consensus-based interdisciplinary guideline. Eur J Cancer 51(14):1989-2007

5. de Berker D, McGregor JM, Mohd Mustapa MF, Exton LS, Hughes BR (2017) British association of dermatologists' guidelines for the care of patients with actinic keratosis 2017. Br J Dermatol 176(1):20-43

6. Overmark M, Koskenmies S, Pitkanen S (2016) A retrospective study of treatment of squamous cell carcinoma in situ. Acta Derm Venereol 96(1):64-67

7. Mittelbronn MA, Mullins DL, Ramos-Caro FA, Flowers FP (1998) Frequency of pre-existing actinic keratosis in cutaneous squamous cell carcinoma. Int J Dermatol 37(9):677-681

8. Efird JT, Friedman GD, Habel L, Tekawa IS, Nelson LM (2002) Risk of subsequent cancer following invasive or in situ squamous cell skin cancer. Ann Epidemiol 12(7):469-475

9. Rees JR, Zens MS, Gui J, Celaya MO, Riddle BL, Karagas MR (2014) Non melanoma skin cancer and subsequent cancer risk. PLoS ONE 9(6):e99674

10. Song F, Qureshi AA, Giovannucci EL et al (2013) Risk of a second primary cancer after non-melanoma skin cancer in white men and women: a prospective cohort study. PLoS Med 10(4):e1001433

11. Robsahm TE, Karagas MR, Rees JR, Syse A (2014) New malignancies after squamous cell carcinoma and melanomas: a population-based study from Norway. BMC Cancer 14:210

12. Official Statistics of Finland (OSF). Population structure [e-publication]. ISSN=1797-5395. Helsinki: Statistics Finland [referred: 11.8.2018]. Access Method: http://www.stat.fi/til/vaerak/ index_en.html. 
13. Korhonen N, Ylitalo L, Luukkaala T et al (2019) Characteristics and trends of cutaneous squamous cell carcinoma in a patient cohort in Finland 2006-2015. Acta Derm Venereol 99(4):412-416

14. Flohil SC, van der Leest RJ, Arends LR, de Vries E, Nijsten T (2013) Risk of subsequent cutaneous malignancy in patients with prior keratinocyte carcinoma: a systematic review and meta-analysis. Eur J Cancer 49(10):2365-2375

15. Whiteman DC, Thompson BS, Thrift AP et al (2016) A model to predict the risk of keratinocyte carcinomas. J Invest Dermatol 136(6):1247-1254

16. Asgari MM, Warton EM, Quesenberry CP, Koralek DO, Taylor M (2014) Risk of subsequent cutaneous squamous cell carcinoma in patients with melanoma. J Am Acad Dermatol 71(3):521-528

17. Wehner MR, Linos E, Parvataneni R, Stuart SE, Boscardin WJ, Chren MM (2015) Timing of subsequent new tumors in patients who present with basal cell carcinoma or cutaneous squamous cell carcinoma. JAMA Dermatol 151(4):382-388

18. Flohil SC, van der Leest RJ, Dowlatshahi EA, Hofman A, de Vries E, Nijsten T (2013) Prevalence of actinic keratosis and its risk factors in the general population: the rotterdam study. J Invest Dermatol 133(8):1971-1978

19. Eder J, Prillinger K, Korn A, Geroldinger A, Trautinger F (2014) Prevalence of actinic keratosis among dermatology outpatients in austria. Br J Dermatol 171(6):1415-1421

20. Werner RN, Sammain A, Erdmann R, Hartmann V, Stockfleth E, Nast A (2013) The natural history of actinic keratosis: a systematic review. Br J Dermatol 169(3):502-518
21. Fernandez-Figueras MT, Carrato C, Saenz X et al (2015) Actinic keratosis with atypical basal cells (AK I) is the most common lesion associated with invasive squamous cell carcinoma of the skin. J Eur Acad Dermatol Venereol 29(5):991-997

22. Bonerandi JJ, Beauvillain C, Caquant L et al (2011) Guidelines for the diagnosis and treatment of cutaneous squamous cell carcinoma and precursor lesions. J Eur Acad Dermatol Venereol 25:1-51 (Suppl 5)

23. Kauvar AN, Arpey CJ, Hruza G, Olbricht SM, Bennett R (2015) Consensus for nonmelanoma skin cancer treatment, part II: squamous cell carcinoma, including a cost analysis of treatment methods. Dermatol Surg 41(11):1214-1240

24. Subramaniam P, Olsen CM, Thompson BS, Whiteman DC, Neale RE, QSkin Sun, and Health Study Investigators (2017) Anatomical distributions of basal cell carcinoma and squamous cell carcinoma in a population-based study in Queensland. Australia JAMA Dermatol 153(2):175-182

25. Terrill PJ, Fairbanks S, Bailey M (2009) Is there just one lesion? The need for whole body skin examination in patients presenting with non-melanocytic skin cancer. ANZ J Surg 79(10):707-712

Publisher's Note Springer Nature remains neutral with regard to jurisdictional claims in published maps and institutional affiliations. 